Anim Cogn. 2014 January ; 17(1): . doi:10.1007/s10071-013-0640-0.

\title{
Apes Communicate about Absent and Displaced Objects: Methodology Matters
}

\author{
Heidi Lyn, \\ University of Southern Mississippi \\ Jamie L. Russell, \\ Yerkes National Primate Research Center \\ David A. Leavens, \\ University of Sussex \\ Kim A. Bard, \\ University of Portsmouth \\ Sarah T. Boysen, \\ The Ohio State University \\ Jennifer A. Schaeffer, and \\ Yerkes National Primate Research Center \\ William D. Hopkins \\ Yerkes National Primate Research Center, and Georgia State University
}

\begin{abstract}
Displaced reference is the ability to refer to an item that has been moved (displaced) in space and/ or time, and has been called one of the true hallmarks of referential communication. Several studies suggest that nonhuman primates have this capability, but a recent experiment concluded that in a specific situation (absent entities) human infants display displaced reference but chimpanzees do not. Here we show that chimpanzees and bonobos of diverse rearing histories are capable of displaced reference to absent and displaced objects. It is likely that some of the conflicting findings from animal cognition studies are due to relatively minor methodological differences, but are compounded by interpretation errors. Comparative studies are of great importance in elucidating the evolution of human cognition, however, greater care must be taken with methodology and interpretation for these studies to accurately reflect species differences.
\end{abstract}

\section{Keywords}

displacement; reference; primate; chimpanzee; bonobo; methodology

Displacement, in the linguistic sense, is the use of a gesture or symbol to refer to an item that is removed in space and/or time. The ability to use displacement is frequently cited as one of several marks of "true reference" (e.g. Cronk 2004; Hockett 1960; Morford and Goldin-Meadow 1997). The distinction, according to language theorists, is that when an item is displaced (most particularly when the item is out of view), both the symbol and the referent are constructed completely within the mental plane. Displaced reference also

Heidi Lyn, Department of Psychology, University of Southern Mississippi, Gulf Coast 730 East Beach Blvd., Long Beach, MS 39560 USA, heidi.lyn@usm.edu. 
requires a social dyad (minimally) to have a common frame of reference, e.g., a common language, or in the case of a deictic point, a common understanding of the gesture's communicative meaning (e.g. Clark 1996). Displacement, more specifically displaced reference, therefore, is one index of socio-cognitive complexity, such as that required for learning language.

Many previous studies have found that chimpanzees communicate about visibly displaced objects (e.g. Leavens et al. 2004; Woodruff and Premack 1979) and show excellent understanding of displacement in a variety of experimental contexts (reviewed by Call 2001). For instance, Woodruff and Premack (1979) showed that chimpanzees informed a human about the location of hidden food, and also developed deceptive communications if that human had proven untrustworthy. Some nonprimate vertebrates, such as dolphins, sea lions, and parrots (e.g. Herman and Forestell 1985; Pepperberg 1999; Pepperberg and Gordon 2005; Schusterman et al. 1993), also have been found to refer to absent entities. In the most extensive experimental test concerning absent reference, Herman and Forestell (1985) showed that a bottlenose dolphin could respond to one paddle to indicate the presence of an object and to another to indicate its absence. Therefore, it is clear from existing literature that apes and other mammals have the ability for displacement.

It is notable that many of the subjects in the above examples have been given prior experiences relevant to displacement. Chimpanzees and bonobos that have acquired symbol systems routinely exhibit displacement in their daily linguistic communication, much the same as human children when they develop language (e.g. Brakke and Savage-Rumbaugh 1996; Gardner et al. 1989; Lyn 2008; Rumbaugh 1977; Savage-Rumbaugh et al. 1993; Savage-Rumbaugh et al. 1986; Savage-Rumbaugh et al. 1978). In all of these cases, apes refer to items that are out of view. In many cases, comprehension and use of displacement is both referential and flexible (Lyn 2012; Lyn et al. 2011; Lyn et al. 2010; Lyn 2010). For example, Lyn et al. (2011) detailed many instances of declarative utterances in chimpanzees and bonobo for items that were out of view, as well as events that happened in the past or were planned for the future. Similarly, when tested under experimental conditions, many, but not all, laboratory chimpanzees request hidden food (Herrmann et al. 2007; Russell et al. 2011).

In a recent comparative experiment, Liszkowski et al. (2009) concluded that chimpanzees do not have displaced reference but that human 12-month-old infants do, and attributed this either to the apes' lack of language or lack of prerequisite socio-cognitive skills. These findings are unexpected due to the prevalence of reports of displaced reference in nonhuman animals, and the fact that some apes have the ability to use symbol systems comparable to that of human infants' early language. Moreover, in the Liszkowski et al. (2009) study, the nature of the referent's absence was unclear, allowing questions to be raised about whether even the human infants in that study exhibited reference to an absent object. Here we conducted a study that tested apes' abilities to refer to displaced and truly absent objects, and tested some apes that used symbol systems. By directly addressing the methodological issues that were problematic in the Liszkowski et al. (2009) study, we expect to clarify the different interpretations about the presence of and skills underlying apes' capability for displacement.

One such interpretive difficulty stems from the contextual meaning of "absent", and its relevance to displacement. In the Liszkowski et al. (2009) study, human infants and the chimpanzees were trained to expect desirable objects at Location A (an elevated platform to the side of a small central table). In the "Absent" condition, the object was removed from Location A and placed in a food cache that was hidden behind and under the table, at the feet of the experimenter. Therefore in their Absent condition, all participants witnessed the 
visible displacement of the object from the vicinity of Location A to the food cache. It is our interpretation that the chimpanzees, but not the human infants, actually tracked the movement of the desirable object: the chimpanzees, but not the humans, pointed to the central location where the desirable object actually was located. The human infants continued to point to Location A, where the desirable location had habitually been located and Liszkowski et al. (2009) interpreted only the human infant behavior as displaced reference.

Any interpretation of differential responses to occluded compared to absent objects is problematic in the Liszkowski et al. study because the referents, the desirable objects, were never absent at any time in any of the experimental procedures - in all trials they were fully present, but simply occluded in different manners. In the condition labeled "occluded", the object was placed underneath a bowl at Location A. In the condition labeled Absent, the object was placed inside a food cache and placed underneath and behind the table at the experimenter's feet (in the middle of the testing area).

Importantly, the number of chimpanzees that gestured to the middle area (where the items were occluded in their Absent condition) was not reported by Liszkowski et al. (2009); rather they report only on the three chimpanzees that eventually pointed to the absent area (the 'correct' response) - all three first indicated the middle area (p. 657). We suggest that the chimpanzees were requesting the food by pointing to the actual location of the food. Consistent with this view, in their supplementary information, Liszkowski and his colleagues reported that the chimpanzees pointed, on average, 9.2 times to the middle (where the food cache was physically located) in the Absent condition, and only 2.0 times in the occluded condition (a difference that approached statistical significance, $p=.052$, p. S5). Another possibility is that when pointing to the middle area, the chimpanzees were requesting that the experimenter get the food by pointing to the experimenter. Since the middle area contained both the experimenter and the food cache, it cannot be determined which (if any) of these interpretations might be correct.

We address these methodological points by designing our study with a condition in which the desirable item is "Truly Absent"; that is, removed completely from the testing area (and thus not retrievable by the experimenter) and a second condition, in which the experimental Absent condition in Liszkowski et al. (2009) was modified. In the original Liszkowski Absent condition, the item is visible moved to an opaque container (out of sight, but the container remains within the test area and retrievable by the experimenter). In the modification (our "Displaced condition"), the food cache was placed inside a container located to the side of the experimenter, which allowed the location of the food cache to be clearly delineated from the location of the experimenter. Instead of pre-supposing a "correct" response, as in Liszkowski et al. (2009), we coded gestures to each location (i.e., to the food cache, to the experimenter, and to the absent area) and recorded, as well, attempts by the apes to elicit responses from the experimenters (i.e., attention-getting gestures: Hopkins et al. 2007; Leavens et al. 2010b; Taglialatela et al. 2011). Therefore, we determined precisely the referent for communicative points with a number of improvements, including conditions that allowed referencing to displaced objects to be distinguished from referencing to truly absent objects.

An additional methodological issue of the Liszkowski et al (2009) study concerns participants' prior history of engaging in pointing: the human infants were preselected to have engaged in pointing, but the chimpanzees were not. According to multiple reports, many but not all apes engage in pointing behavior (Leavens et al. 2005; Leavens et al. 2004; Leavens et al. 1996). In particular, about $50 \%$ of institutionalized chimpanzees point in triadic contexts compared to $100 \%$ of language-trained chimpanzees (Leavens et al. 2010a; 
Leavens and Bard 2011). Moreover, 100\% of language-trained apes - including bonobos, gorillas, and orangutans - point manually (Leavens et al. 2010a). It is unclear whether the chimpanzees in the Liszkowski, et al. (2009) study were known to point prior to the experiment, although apparently all did point at least once during the experiment (Liszkowski, personal communication, 11 January 2011). For our study, we selected apes with a prior history and facility with pointing as a communicative gesture, making our sample more comparable to the human infants tested by Liszkowski et al. (2009).

Finally, we extend the consideration of ape displacement abilities by including a sample of a closely-related species, bonobos, from the Great Ape Trust of Iowa (GATI). No species differences were found between chimpanzees and bonobos in earlier studies that explored several communicative and cognitive tasks (Russell et al. 2011). However, the GATI bonobos were reared in a linguistically-enriched environment that had been shown previously to increase comprehension of communicative signals compared to the standardreared apes, such as the chimpanzees reared at research facilities or zoos (see Lyn et al. 2010; Russell et al. 2011). This opportunistic sampling permitted us to test for the generality of behavioral outcomes between standard-reared chimpanzees and language-competent bonobos in the display of displaced reference.

\section{Predictions}

We expect that the apes follow and gesture toward the real location of the food. We therefore predict that: 1) the apes will gesture to the container of the food cache in the modified absent condition (Displaced) in which the cache is not removed from the area; 2) In the Truly Absent condition, the apes may a) gesture to other locations - we do not necessarily expect the apes to point to the food cache container in this condition b) exhibit attention-getting behaviors to the experimenter or c) refrain from gesturing; 3 ) the apes will be less likely to gesture when the food is truly absent than when it is displaced from its habitual location. If we follow the predictions in Liszkowski et al (2009) study, should the apes gesture to the container (the habitual location) in either condition, then we could conclude that they show displaced reference like the human infants in Liszkowski et al (2009). If, however, language skills are required for displaced reference, then we would expect only the language-competent bonobos to point to the container.

\section{Method}

\section{Subjects}

Nine chimpanzees (Pan troglodytes) from the Yerkes National Primate Research Center (YNPRC: 7 female and 2 male, age range: 14-39 yrs.) and four bonobos (Pan paniscus) from the Great Ape Trust of Iowa (GATI: 3 female and 1 male, age range 10-39 yrs.) served as subjects. All 13 apes had been tested previously on a pointing production task (Russell et al. 2011) and had engaged in communicative pointing behavior on at least 3 out of 4 trials, with a minimum of 2 correct trials.

\section{Procedure}

All apes were tested in their home enclosures. Experimenter 1 sat on a stool centered approximately one meter from the cage front. An insulated opaque cooler with a lid ("the cooler") held a single transparent container of food (the "food cache") and was placed approximately 0.5 meters from the cage mesh on one side of Experimenter 1 (see Figure 1). An empty, clear container was placed on top of a second stool approximately 0.5 meters from the cage mesh (the "container") on the opposite side of Experimenter 1 from the cooler. The locations of the cooler and the container (left or right of Experimenter 1) were 
counterbalanced across sessions. A second experimenter (Experimenter 2) sat approximately 1 meter behind Experimenter 1. During the Displaced condition, the experimenter would manipulate the food and then replace it in the cooler. During the Truly Absent Condition, after Experimenter 1 manipulated the food item, Experimenter 2 took the food cache, and left the test area through the nearest doorway, closing the door behind her. On all trials the behavior of the ape was videotaped for later coding.

Demonstrations-Trials 1-4 were demonstrations to create an expectation that food would be in the container (as in Liszkowski et al., 2009) as follows:

When the subject was watching, Experimenter 1 removed the food cache from the cooler, took a piece of food from inside, and placed it in the container. The experimenter then replaced the food cache into the cooler, picked up the piece of food from the container and gave it to the ape to eat. The experimenter minimized eye contact throughout the demonstration and did not acknowledge any gestures from the ape. This routine was designed to instill an expectation of food placement into the container.

\section{Test Trials ( 2 conditions)}

Displaced Condition: While facing the subject, Experimenter 1 took the food cache from the cooler, took a piece of food, and began to place the piece of food in the container as during the demonstrations. But in this condition, the Experimenter put the piece back into the food cache, and replaced the cache in the cooler, closing the lid so that no food was visible. This condition mimics the procedure in Liszkowski et al.'s "absent" condition, with the modification that the locations of the food cache and the experimenter are clearly separated.

Truly Absent Condition: While facing the subject, Experimenter 1 took the food cache from the cooler, took a piece of food, and began to place the piece of food in the container as during the demonstrations. In this condition, Experimenter 1 put the piece back into the food cache, and handed the food cache to Experimenter 2, who took the food and walked out of the test area. The lid to the cooler was left open so that the subjects could see that the cooler was empty.

Subsequent to the four demonstrations, eight trials were run in the Displaced condition, and eight trials run in the Truly Absent condition, counterbalanced for order across the 16 trials. Subjects were allowed 90 seconds in which to respond and then, if they did not gesture, the trial was ended. If the subject made a gesture (i.e., a point - see below for definitions) to either the cooler or the container, the trial ended. At approximately 30 seconds, 50 seconds, and 80 seconds into the trial, if a given subject did not point to the container or the cooler, then the subject was offered vocal and gestural encouragement, similar to the methodology of Liszkowski, et al. (2009). For example, Experimenter 1 might encourage the subject by asking, "Do you want me to get you something?" while gesturing to the two locations simultaneously.

Gestures to the experimenter were given a verbal response (e.g. "Would you like something?"), and the trial continued. Again, points to either the cooler or the container ended the trial. In the Truly Absent condition, when the trial was over, Experimenter 2 retrieved the food cache from outside the test area and gave it to Experimenter 1. At the completion of trials in both the Displaced and Truly Absent Conditions, Experimenter 1 took a piece of food from the cache, placed the food in the container, and then gave the food to the subject (repeating the demonstrations, and reinstating the expectation of food in the container). 


\section{Coding and Reliability}

Videotapes of the trials were coded for all communicative gestures, defined as behaviors with a clear reference or communicative purpose. A manual point was defined as a deliberate extension or movement of the arm, with at least one finger extended, that was directed toward an object, an area, or a person without another immediate purpose, such as probing the environment (e.g. Leavens et al. 1996).A lip point was defined as an extension of the lip, usually through the cage mesh, directed toward an object, an area, or a person. The ape's face was directed generally toward the experimenter or in the direction of the gesture. Lip points were included specifically because one chimpanzee used lip points almost exclusively when gesturing communicatively (see e.g. Enfield et al. 2007; Enfield 2001; Wilkins (2003) for discussion of lip-pointing among humans). Manual and lip points were summed into the category of Point.

All points were coded as directed toward 1) the container, 2) the Experimenter, 3) the cooler, or 4) "Other". This latter category included points directed toward something outside the test area (e.g. high up, or toward the rear of the cage). Attention-getting behaviors, such as cage bangs (where the ape bangs a fist or arm against the cage material), hand shakes (raising a hand and shaking it - usually in the direction of the experimenter), or claps (clapping both hands together) were wrapped into the Other gesture category, due to a relatively small number of other-directed points. Occasionally, these Other points appeared to indicate the place where Experimenter 2 had left the area. However, these points were frequently off-camera as the camera was focused on the container, the experimenter, and the cooler. Therefore points toward all other areas of the cage are categorized together as Other gestures.

\section{Reliability}

All trials were coded by the first author and $23 \%$ of the trials were also coded for reliability assessment by an independent coder (the second author) who was as blind as possible to the trial type (coding started from the moment the cooler closed or the second experimenter left and the coders were instructed to focus on the ape only). Reliability agreement was scored when the coders both indicated the incidence (or lack thereof) of a gesture to a particular area. Raters agreed on the presence of a gesture $91.7 \%$ of the time (Cohen's Kappa: $k=.83$ ). Agreements on specific point types were $87.5 \%$ (Cohen's Kappa: $\kappa=.75$ ) for gestures toward the container, $89.5 \%$ for gestures to the experimenter, and $91.7 \%(\kappa=.83)$ for both points to the cooler and Other gestures.

\section{Data Analysis}

Repeated-measure ANOVAs were conducted to determine if each gesture varied by condition (Truly Absent, Displaced) as a within-subjects variable and species (Chimpanzee, Bonobo) as a between-subjects variable (of course, it is important to bear in mind that in our design, species and rearing history are confounded--we are comparing standard nurseryreared chimpanzees with environmentally enriched bonobos). Different types of gestures provoked different responses by the experimenter, and since some responses were not independent, individual analyses were run for each gesture. To further explore differential gesturing by the apes across conditions and experimenter responses, we also ran a single repeated-measure ANOVA in which the gestures were defined as "ending" points (points to the container and to the cooler that ended the trial) or "non-ending" gestures (points to the experimenter and Other gestures that did not end the trial): this was a 2 (point type) by 2 (condition) by 2 (species) repeated-measures ANOVA. This second analysis helps us to determine whether different experimenter responses had any systematic effects on the apes' gestural signaling. 


\section{Results}

In the Displaced condition, 10/13 (77\%) of the apes referred to the empty container at least once with no preceding points either to the experimenter or to a non-experimental area. Similarly, 9/13 (70\%) of the apes referred to the container in the Truly Absent condition. When the apes indicated the container without preceding points, $52 \%$ of points in the Displaced condition and $72 \%$ of points in the Truly Absent condition were initiated before any prompts were given. Therefore, the apes fulfilled the requisite behaviors that, according to Liszkowski, et al. (2009), warranted their conclusion that their human infants engaged in displaced reference.

The percentage of trials in which the apes pointed to the container is illustrated in Figure 2. The apes did not point differentially to the container across the conditions $(F(1,11)=2.82$, $\left.P=.12, \eta^{2}=.20\right)$ nor was there a main effect of species for container-directed points $(F(1,11)$ $\left.=3.62, P=.08, \eta^{2}=.25\right)$. Chimpanzees and bonobos also did not differentially refer to the container across the two conditions as there was no significant interaction between species and condition $\left(F(1,11)=0.64, P=.44, \eta^{2}=.055\right)$. Given the large effect size, it is worth noting that there was a trend for the bonobos to gesture to the container more than the chimpanzees, and a trend for more gestures to the container to be made in the Displaced than the Truly Absent condition. Importantly, the intercept of the analysis was significantly different from zero, supporting the assertion that the apes indicated the container more than would be expected by chance $(F(1,11)=30.94, P<.001)$. These results confirm that the apes in our study did indicate the "food absent area", the container that usually held the food item, unlike the chimpanzees in Liszkowski et al. (2009) study.

Importantly, 9/13 apes indicated the cooler more frequently than the container in the Displaced condition. For points to the cooler, there were no main effects of species $(F(1,11)$ $\left.=0.50, P=.49, \eta^{2}=.04\right)$ or of condition $\left(F(1,11)=2.13, P=.17, \eta^{2}=.16\right)$, but there was a significant interaction between condition and species $\left(F(1,11)=7.59, P=.02, \eta^{2}=.41\right.$; See Fig. 2). Post-hoc t-tests indicate that the chimpanzees pointed to the cooler significantly more frequently in the Displaced condition than in the Truly Absent condition $(t(8)=3.65$, $P=.006)$, but the bonobos pointed to the cooler at similar rates in both conditions $(t(3)=0.88$, $P=.44)$. This supports the conclusion that the chimpanzees might track the actual location of the food (the cooler), when it is present but hidden in a new location (in the Displaced condition). The bonobos, however, gesture similarly in both conditions.

Looking at this finding in light of the possible differential experimenter responses, the analysis of "ending" points (collapsing points to the cooler and the container into a new code of "ending points" and all other gestures as "non-ending gestures") revealed a main effect of condition $\left(F(1,11)=10.32, P=.008, \eta^{2}=.48\right)$ with significantly more ending points in the Displaced condition than the Truly Absent condition. There was also a main effect of species $\left(F(1,11)=5.33, P=.041, \eta^{2}=0.33\right)$ with bonobos making significantly more ending points overall than the chimpanzees. However, there was a significant interaction between condition and species $(F(1,11)=5.13, P=.045,=0.32)$, showing that this difference in ending points across conditions was mainly driven, again, by the differential responding of the chimpanzees.

Within the category of non-ending points, points to the experimenter did not differ significantly across conditions or across species (Figure 3 panel a): there were no significant main effects (condition: $\left(F(1,11)=0.47, P=.51, \eta^{2}=.04\right)$; species: $(F(1,11)=0.35, P=.56$, $\left.\eta^{2}=.03\right)$. The interaction between condition and species was also not significant $(F(1,11)=$ 3.12, $P=.10, \eta^{2}=.22$ ), although there was a trend in the Displaced condition for the chimpanzees, more than the bonobos, to gesture to the experimenter. This finding suggests 
that points to the experimenter were general communicative gestures and were therefore were not differentially used across the conditions.

The difference in non-ending points, therefore, seems to be driven by the Other gestures. Bonobos made significantly fewer Other gestures overall compared with the chimpanzees: there was a significant main effect of species $\left(F(1,11)=6.48, P=.03, \eta^{2}=.37\right)$. There was no main effect of condition $\left(F(1,11)=3.23, P=.09, \eta^{2}=.24\right)$, but there was a significant interaction found in Other gestures $\left(F(1,11)=6.17, P=.03, \eta^{2}=.36\right.$; Figure. 3 panel b): Chimpanzees made significantly more other gestures in the Displaced compared to the Truly Absent condition $(t(8)=3.41, P=.009)$, but, again, bonobos showed no difference across conditions $(t(3)=1.00, P=.39)$. Because these other gestures were primarily attention-getting gestures (without specific referents), this finding may again indicate that the chimpanzees were aware of the availability of the food in the Displaced condition and therefore exerted more effort to communicate in that condition.

To try to clarify this difference in gesturing between the chimpanzees and bonobos, we analyzed the trials in which the apes made no gesture of any kind. In these "no gesture" trials, there was a significant main effect of species, $\left(F(1,11)=8.57, P=.015, \eta^{2}=0.44\right.$; Figure 4), no significant main effect of condition $\left(F(1,11)=8.57, P=.015, \eta^{2}=0.44\right)$, and a significant interaction between condition and species $\left(F(1,11)=5.81, P=.035, \eta^{2}=0.35\right)$. These findings were driven by the fact that the bonobos always gestured $(0 \%$ no gesture trials for the bonobos), but the chimpanzees gestured differentially. The chimpanzees were significantly more likely to refrain from making any gestures in the Truly Absent condition compared to the Displaced condition. This finding is perhaps the strongest evidence that the chimpanzee displayed their understanding of the unavailability of the food items.

\section{Discussion}

The results of the current study demonstrate that, contrary to the findings of Liszkowski et al. (2009), apes do communicate about absent entities: the apes in the current study gestured to the empty container in both conditions, when the desired object was visibly displaced, but still present (as in the Liszkowski et al. (2009) "absent" referent condition) as well as when it was absent altogether (our Truly Absent condition). The apes tested here differed from those of Liszkowski et al. (2009) in that they indicated the absent entities by pointing to the empty container after being led to expect the desired object to be in the container (Fig. 5).

We also found support for our hypotheses concerning chimpanzees' abilities to track the actual location of the desired object, which was clarified with our methodological changes. In particular, the chimpanzees were significantly more likely to indicate the cooler when the food was displaced to the cooler than when the food was actually absent. This finding suggests that these chimpanzees track the current location of the food and frequently gesture toward that location. Therefore when the chimpanzees gestured toward the middle of the apparatus in the Liszkowski et al. (2009) study, they may have been requesting the food that had been placed there under the table. Indeed, Liszkowski et al. reported that their "chimpanzees produced more unspecific points to the middle in the Absent Referent condition [the condition in which the food was actually located in the middle] than in the Occluded Referent condition" (2009, Supplementary Methods, p. S5).

We predicted that the apes would be less likely to gesture to the experimenter or make attention-getting gestures when the desired object had been removed entirely from the testing environment, but this hypothesis was only partially supported. We did find that the chimpanzees, but not the bonobos, refrained from gesturing when the desired object was truly absent from the test area, but the bonobos were just as likely to gesture in both 
conditions. Perhaps this is due to their differential pre-experimental histories: the chimpanzees lived in a standard laboratory setting, where it was often the case that food was carried away, and, once removed, it would usually not be returned. In contrast, the bonobos lived in an environment enriched with a symbol system and with caregivers who often would respond positively to requests for food to be returned after it had been carried away. The bonobos also had pre-experimental communicative interactions about items that were not just out of sight, but had happened in the past, or were planned for the future (Lyn et al. 2011; Brakke and Savage-Rumbaugh 1996; Savage-Rumbaugh et al. 1986). Although several studies have shown that apes reared in a socio-linguistic environment have a better understanding of communicative points by their caregivers (see Lyn 2010; Lyn et al. 2010; Russell et al. 2011), we do not have any evidence that this impacted performance in this displacement task.

These findings seem to contradict the recent findings by Liszkowski et al. (2009) that showed that chimpanzees did not indicate containers of absent food, even after multiple trials. However, those chimpanzees did indicate the experimenter and/or the location of the hidden food - also "following the food" as we have shown here. However, unlike the Liszkowski et al. (2009) chimpanzees, the apes in the present study also indicated the container, meeting Liszkowski et al.'s operational criterion for communicating about absent entities. In addition, these responses were sometimes their first gestural response, and were made before any cues were given - both requirements for displaced referential indication according to Liszkowski et al. (2009). Our results demonstrate that, with just a slight modification of the physical layout, the apes performed more similarly to the children, and less like the chimpanzees in the study by Liszkowski et al. (2009) (Figure 5).

However, it is important to point out the differences between the language-using bonobos and the language-naive chimpanzees in our study. While the chimpanzees did indicate the container and did so without previous points, this type of response was less frequent in the chimpanzee group than in the bonobo group in both conditions (approaching significance; $P=.08$ ). It is possible that with an increased sample of language-using apes, this difference would be significant. These results and the differences noted above are consistent with our previous findings that rearing and living environment greatly affect the cognitive and communicative capacities of apes (Lyn 2010; Lyn et al. 2010; Russell et al. 2011; Leavens and Bard 2011; Leavens et al. 2010b). However, in the current study, the species variable is confounded with rearing differences, so further research is required to distinguish the cause of these differences.

These findings exemplify the problematic interpretations of some types of cross-species experiments (Boesch 2007; Mulcahy and Call 2009). We know from studies of both human children (e.g. Deak et al. 2000; Moore and D'Entremont 2001) and nonhumans (e.g. Hattori et al. 2010) that even minor changes in physical context can lead to large changes in response characteristics (see also Boesch 2008; Boesch 2007). Frequently, these methodological changes are not recognized, and so interpretation of the data is problematic; it is not uncommon that behavioral differences between representatives of different species are attributed to differences in evolutionary histories when, in fact, these differences are confounded with substantial differences in the organisms' pre-experimental experiences and in experimental procedures (Leavens \& Bard 2011).

When comparing humans and nonhuman primates, researchers frequently sample representatives from different species, at different ages, with dissimilar pre-experimental social histories, and, if they find a difference, frequently interpret that difference as evidence for human cognitive superiority (Leavens et al. 2008). For example, Tomasello and Call (1997) in noting evidence that young human children imitated demonstrated actions more 
faithfully than chimpanzees (e.g. Whiten et al. 1996), referred to the former response pattern as "true imitation" and the latter as mere "emulation". According to Tomasello and Call (1997), only "true imitation" implied that the participants understood the intentionality of the demonstrator. However, recently Horowitz (2003) demonstrated that human adults acted more like the chimpanzees, emulating rather than directly imitating the behavior of a model, contradicting the assumptions of Tomasello and Carpenter's (2005) cognitive model.

Similarly, Povinelli et al. (1999) demonstrated that chimpanzees used the gaze direction of human demonstrators to find food more effectively than did younger human children in an experimental condition in which the experimenter's gaze was directed away from a baited container, but directed toward the correct hemispace. The chimpanzees' superior performance in this condition was interpreted by Povinelli et al. (1999) as evidence for inferior cognitive representations of visual perspective. However, Thomas et al. (2008) showed that human adults responded more like the chimpanzees under these experimental conditions. Again, apes' performance was incorrectly interpreted as evidence for cognitive inferiority on the basis of a difference in behavior.

Thus, apart from the difficulty in creating equivalent methodological procedures for humans and chimpanzees, there appears to be a bias towards interpreting chimpanzee responses as inferior to human responses whenever they merely differ. This highlights the difficulty in elucidating cognitive mechanisms, particularly when experiments use flawed sampling procedures or have little control over subject variables, (e.g. Bulloch et al. 2008; Furlong et al. 2008; Hostetter et al. 2007; Leavens et al. 2008; Thomas et al. 2008). There is little question that future cross-species studies are of tremendous importance in further delineating the evolution of human cognition. However, any conclusions drawn from these studies must withstand close methodological and interpretive scrutiny.

\section{Acknowledgments}

Funding for this study was provided by NIH grants NS-42867, HD-56232 and HD-60563.

The authors wish to thank the staff at YNPRC and Bill Fields and the research staff at GATI for their assistance in data collection. American Psychological Association and Institute of Medicine guideines for the ethical treatment of animals were adhered to during all phases of this study.

\section{References}

Boesch C. What makes us human (Homo sapiens)? The challenge of cognitive cross-species comparison. Journal of Comparative Psychology. 2007; 121:227-240.10.1037/0735-7036.121.3.227 [PubMed: 17696649]

Boesch C. Taking development and ecology seriously when comparing cognition: reply to Tomasello and Call (2008). Journal of Comparative Psychology. 2008; 122:453455.10.1037/0735-7036.122.4.453 [PubMed: 19014271]

Brakke KE, Savage-Rumbaugh ES. The development of language skills in Pan - II. Production. Language and Communication. 1996; 16:361-380.

Bulloch MJ, Boysen ST, Furlong EE. Visual attention and its relation to knowledge states in chimpanzees, Pan troglodytes. Animal Behaviour. 2008; 76:1147-1155.

Call J. Chimpanzee social cognition. Trends in Cognitive Sciences. 2001; 5

Clark, H. Using language. Cambridge University Press; Cambridge, England: 1996.

Cronk L. Continuity, displaced reference, and deception. Behavioral and Brain Sciences. 2004; 27:510-511.10.1017/s0140525x04300117

Deák GO, Flom RA, Pick AD. Effects of gesture and target on 12- and 18-month-olds' joint visual attention to objects in front of or behind them. Developmental Psychology. 2000; 36:511523.10.1037/0012-1649.36.4.511 [PubMed: 10902702] 
Enfield NJ. Lip-pointing: A discussion of form and function with reference to data from Laos. Gesture. $2001 ; 1: 185-212$.

Enfield NJ, Kita S, De Ruiter JP. Primary and secondary pragmatic functions of pointing gestures. Journal of Pragmatics. 2007; 39:1722-1741.10.1016/j.pragma.2007.03.001

Furlong EE, Boose KJ, Boysen ST. Raking it in: the impact of enculturation on chimpanzee tool use. Animal Cognition. 2008; 11:83-97. [PubMed: 17516100]

Gardner RA, Gardner BT, Van Cantfort TE. Teaching sign language to chimpanzees 324. 1989

Hattori Y, Kuroshima H, Fujita K. Tufted capuchin monkeys (Cebus apella) show understanding of human attentional states when requesting food held by a human. Animal Cognition. 2010; 13:8792.10.1007/s10071-009-0248-6 [PubMed: 19517147]

Herman LM, Forestell PH. Reporting presence or absence of named objects by a language-trained dolphin. Rutgers University Symposium: The question of animal cognition (1985, New Brunswick, New Jersey). Neuroscience and Biobehavioral Reviews. 1985; 9:667-681. [PubMed: 4080284]

Herrmann E, Call J, Hernandez-Lloreda MV, et al. Humans have evolved specialized skills of social cognition: The cultural intelligence hypothesis. Science. 2007; 317:1360-1366.10.1126/science. 1146282 [PubMed: 17823346]

Hockett CF. The origin of speech. Scientific American. 1960; 203:88-96. [PubMed: 13683472]

Hopkins WD, Taglialatela JP, Leavens DA. Chimpanzees differentially produce novel vocalizations to capture the attention of a human. Animal Behaviour. 2007; 73:281-286. [PubMed: 17389908]

Horowitz AC. Do humans ape? Or do apes human? Imitation and intention in humans (Homo sapiens) and other animals. Journal of Comparative Psychology. 2003; 117:325-336. [PubMed: 14498809]

Hostetter AB, Russell JL, Freeman H, Hopkins WD. Now you see me, now you don't: evidence that chimpanzees understand the role of eyes in attention. Animal Cognition. 2007; 10:55-62. [PubMed: 16847659]

Leavens DA, Bard KA. Environmental influences on joint attention in great apes: implications for human cognition. Journal of Cognitive Education and Psychology, Special Issue on "Culture and Cognition”. 2011; 10:9-31.

Leavens DA, Bard KA, Hopkins WD. BIZARRE chimpanzees do not represent "the chimpanzee." Commentary on target article by Henrich, Heine \& Norenzayan, The weirdest people in the world? Behavioral and Brain Sciences. 2010a; 33:100-101. [PubMed: 20550740]

Leavens DA, Hopkins WD, Bard KA. Understanding the point of chimpanzee pointing: epigenesis and ecological validity. Current Directions in Psychological Science. 2005; 14:185-189. [PubMed: 18159225]

Leavens DA, Hopkins WD, Bard KA. Indexical and referential pointing in chimpanzees (Pan troglodytes). Journal of Comparative Psychology. 1996; 110:346-353. [PubMed: 8956506]

Leavens DA, Hopkins WD, Bard KA. The heterochronic origins of explicit reference. The shared mind: Perspectives on intersubjectivity. 2008

Leavens DA, Hopkins WD, Thomas R. Referential communication by chimpanzees (Pan troglodytes). Journal of Comparative Psychology. 2004; 118:48-57. [PubMed: 15008672]

Leavens DA, Russell JL, Hopkins WD. Multimodal communication by captive chimpanzees (Pan troglodytes). Animal cognition. 2010b; 13:33-40.10.1007/s10071-009-0242-z [PubMed: 19504272]

Liszkowski U, Schäfer M, Carpenter M, Tomasello M. Prelinguistic infants, but not chimpanzees, communicate about absent entities. Psychological Science. 2009; 20:654-660.10.1111/j. 1467-9280.2009.02346.x [PubMed: 19476595]

Lyn, H. Artificial symbol systems in dolphins and apes: analogous communicative evolution or evidence for basic communicative rules? The Evolution of Language. Proceedings of the 7th International Conference (EVOLANG7); 2008.

Lyn, H. Apes and the evolution of language: taking stock of 40 years of research. In: Vonk, J.; Shackelford, TK., editors. Oxford Handbook of Comparative Evolutionary Psychology. Oxford University Press; Oxford, UK: 2012. p. 356-378. 
Lyn H. Environment, methodology, and the object choice task in apes: evidence for declarative comprehension and implications for the evolution of language. Journal of Evolutionary Psychology. 2010; 8:333-349.10.1556/JEP.8.2010.4.3

Lyn H, Greenfield PM, Savage-Rumbaugh S, et al. Nonhuman primates do declare! A comparison of declarative symbol and gesture use in two children, two bonobos, and a chimpanzee. Language and Communication. 2011; 31:63-74.10.1016/j.langcom.2010.11.001 [PubMed: 21516208]

Lyn H, Russell JL, Hopkins WD. The impact of environment on the comprehension of declarative communication in apes. Psychological Science. 2010; 21:360-365.10.1177/0956797610362218 [PubMed: 20424069]

Moore C, D'Entremont B. Developmental changes in pointing as a function of attentional focus. Journal of Cognition and Development. 2001; 2:109-129.10.1207/s15327647jcd0202_1

Morford JP, Goldin-Meadow S. From here and now to there and then: The development of displaced reference in homesign and English. Child Development. 1997; 68:420-435.10.2307/1131669 [PubMed: 9249958]

Mulcahy NJ, Call J. The performance of bonobos (Pan paniscus), chimpanzees (Pan troglodytes), and orangutans (Pongo pygmaeus) in two versions of an object-choice task. Journal of Comparative Psychology. 2009; 123:304-309. doi: http://dx.doi.org/10.1037/a0016222. [PubMed: 19685972]

Pepperberg, IM. The Alex studies: cognitive and communicative abilities of grey parrots. Harvard University Press; Cambridge, Massachusetts: 1999.

Pepperberg IM, Gordon JD. Number Comprehension by a Grey Parrot (Psittacus erithacus), Including a Zero-Like Concept. Journal of Comparative Psychology. 2005; 119:197209.10.1037/0735-7036.119.2.197 [PubMed: 15982163]

Povinelli DJ, Bierschwale DT, Ĉech CG. Comprehension of seeing as a referential act in young children, but not juvenile chimpanzees. British Journal of Developmental Psychology. 1999; 17:37-60.10.1348/026151099165140

Rumbaugh DM. Language learning by a chimpanzee: the Lana project. Communication and behavior. 1977:xxii, 312.

Russell JL, Lyn H, Schaeffer JA, Hopkins WD. The role of socio-communicative rearing environments on the development of social and physical cognition in apes. Developmental Science. 2011; 14:1459-1470. [PubMed: 22010903]

Savage-Rumbaugh ES, McDonald K, Sevcik RA, et al. Spontaneous symbol acquisition and communicative use by pygmy chimpanzees (Pan paniscus). Journal of Experimental Psychology: General. 1986; 115:211-235. [PubMed: 2428917]

Savage-Rumbaugh ES, Murphy J, Sevcik RA, et al. Language comprehension in ape and child. Monographs of the Society for Research in Child Development. 1993; 58:v 221.

Savage-Rumbaugh ES, Rumbaugh DM, Boysen S. Symbolic communication between two chimpanzees (Pan troglodytes). Science. 1978; 201:641-644. [PubMed: 675251]

Schusterman, RJ.; Gisiner, R.; Grimm, BK.; Hanggi, EB. Behavior control by exclusion and attempts at establishing semanticity in marine mammals using match-to-sample paradigms. In: Roitblat, HL.; Herman, LM.; Nachtigall, PE., editors. Language and communication: comparative perspectives. Comparative cognition and neuroscience. Lawrence Erlbaum Associates, Inc; Hillsdale, NJ, US: 1993. p. 249-274.

Taglialatela JP, Russell JL, Schaeffer Ja, Hopkins WD. Chimpanzee vocal signaling points to a multimodal origin of human language. PloS one. 2011; 6:e18852.10.1371/journal.pone.0018852 [PubMed: 21533079]

Thomas E, Murphy M, Pitt R, et al. Understanding of visual attention by adult humans (Homo sapiens): a partial replication of Povinelli, Bierschwale, and ech (1999). Journal of Comparative Psychology. 2008; 122:428-436.10.1037/0735-7036.122.4.428 [PubMed: 19014266]

Tomasello, M.; Call, J. Primate cognition. Oxford University Press; New York: 1997.

Tomasello M, Carpenter M. The Emergence of Social Cognition in Three Young Chimpanzees. Monographs of the Society for Research in Child Development. 2005; 70:1-136.

Whiten A, Custance DM, Gómez JC, et al. Imitative learning of artificial fruit processing in children (Homo sapiens) and chimpanzees (Pan troglodytes). Journal of Comparative Psychology. 1996; 110:3-14.10.1037/0735-7036.110.1.3 [PubMed: 8851548] 
Wilkins, D. Why pointing with the index finger is not a universal (in sociocultural and semiotic terms). In: Kita, S., editor. Pointing: where language, culture, and cognition meet. Erlbaum; Mahwah, N. J: 2003. p. 171-215.

Woodruff G, Premack D. Intentional communication in the chimpanzee: the development of deception. Cognition. 1979; 7:333-362. 
a.

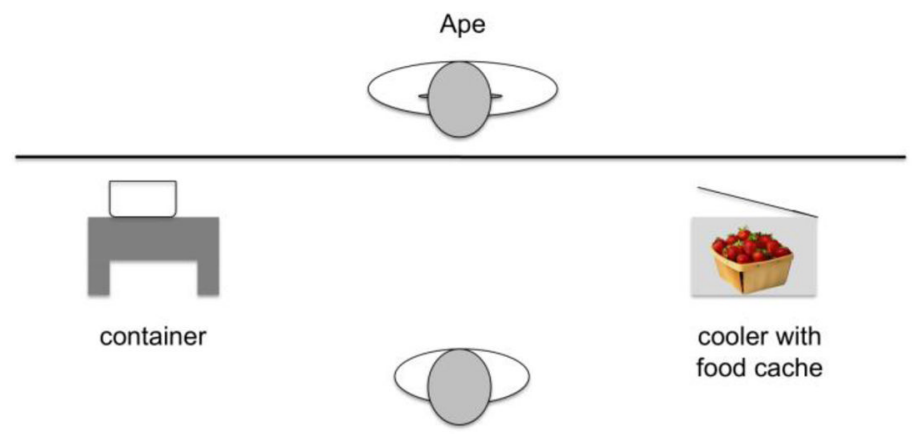

Experimenter 1

\section{Displaced Condition}

b.

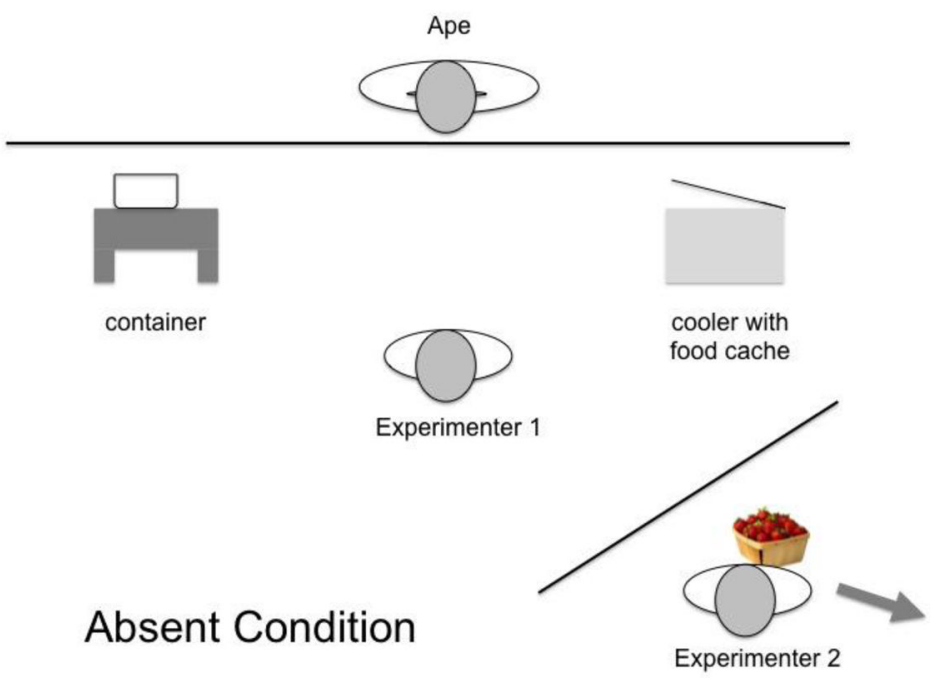

Fig. 1.

The experimental set-up for each condition. Labels indicate depictions of the container and the cooler. These locations were counterbalanced for left and right side across the trials. The arrow in $\mathrm{b}$. indicates the movement of Experimenter 2 leaving the immediate area with the food cache. 


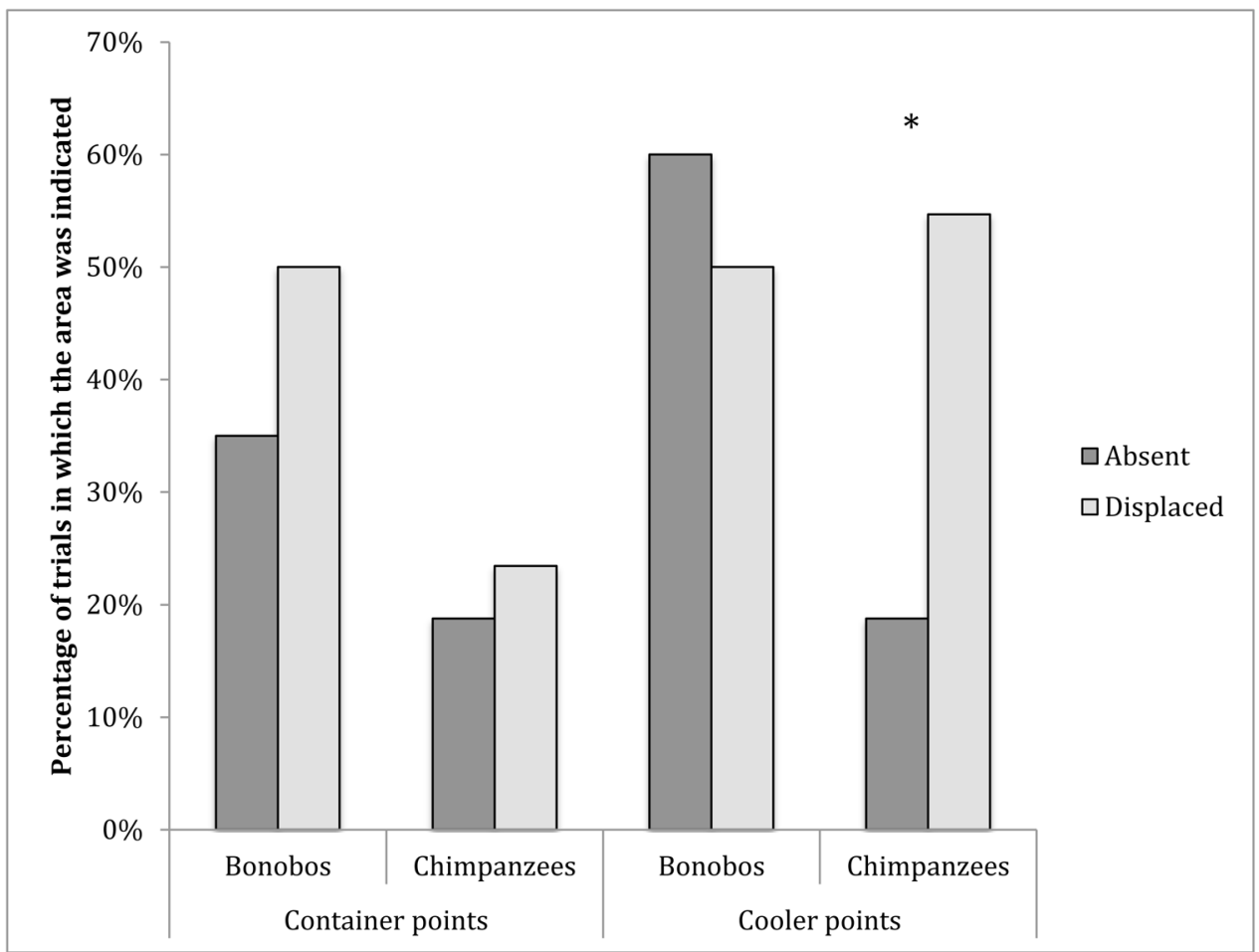

Fig. 2.

The mean percentage of trials in which the participants pointed to the container or to the cooler in the each condition. * conditions are significantly different $P<.01$ 


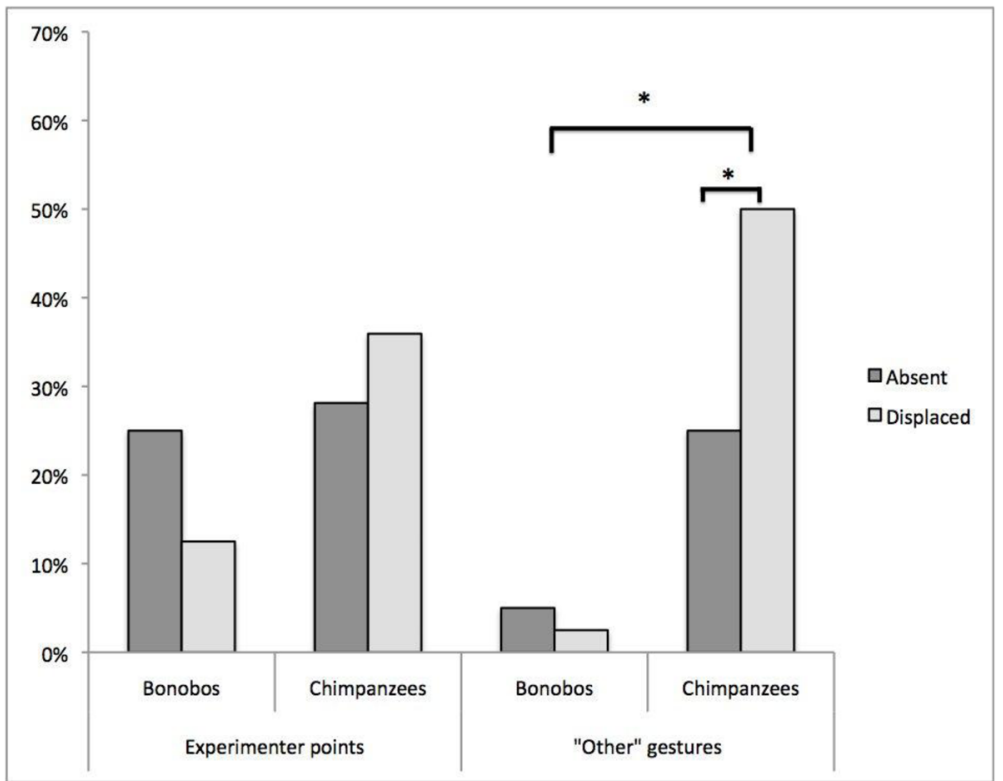

Fig. 3.

The mean percentage of trials in which the participants made at least one gesture to the experimenter or at least one Other gesture (points not directed at the areas or the experimenter and attention-getting gestures). * conditions are significantly different, $P<.05$ 


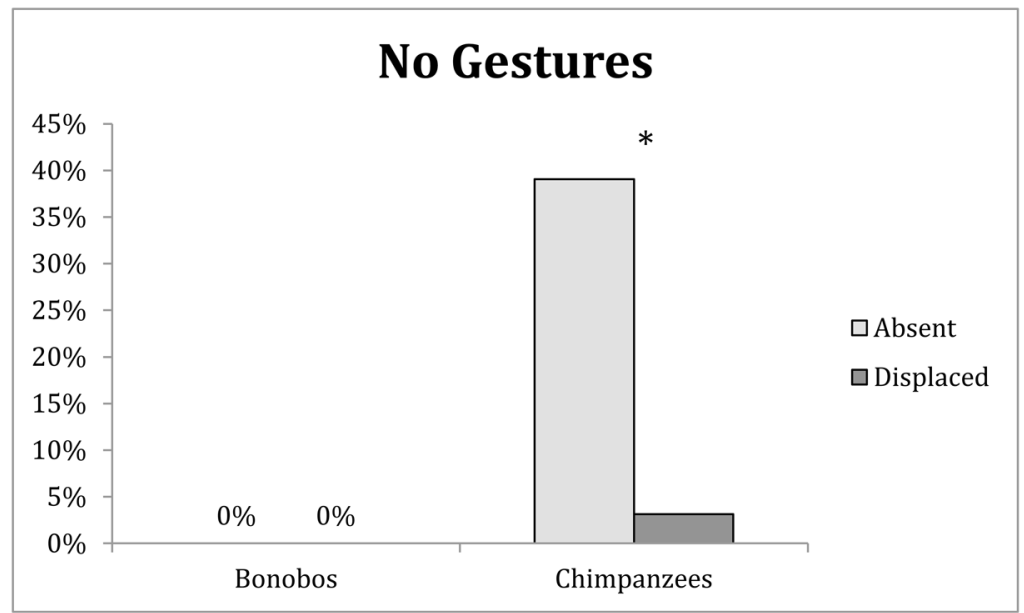

Fig. 4.

The mean percentage of trials in which the participants made no gesture of any kind. * conditions are significantly different, $P<.05$ 


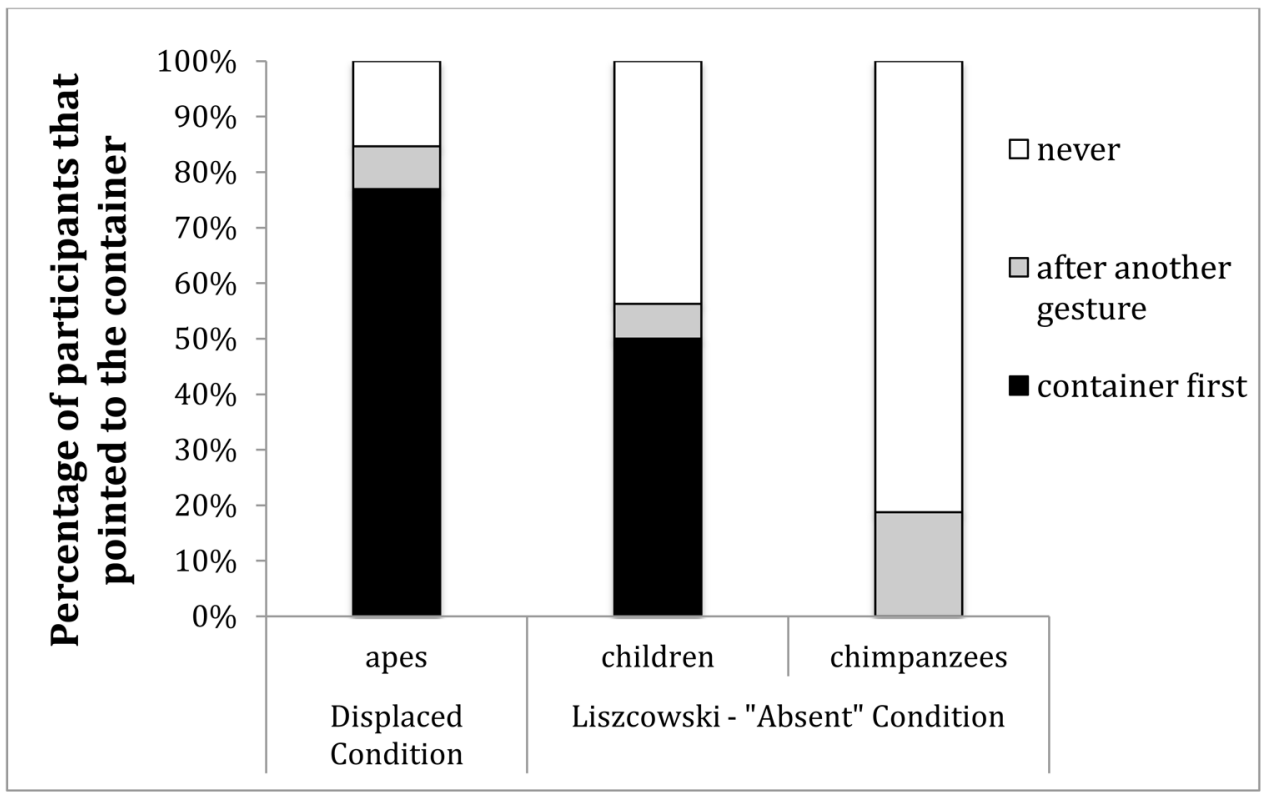

Fig. 5.

The percentage of participants in each study (our Displaced Condition compared to Lizscowski et al.'s equivalent Absent Condition) that either: pointed to the absent area at least once without preceding points to another location; pointed to the absent area with preceding points to another location; or never pointed to the absent area. 